\title{
Heat-Transfer Phenomena Across Mold Flux by Using the Inferred Emitter Technique
}

\author{
KEZHUAN GU, WANLIN WANG, JUAN WEI, HIROYUKI MATSUURA, \\ FUMITAKA TSUKIHASHI, IL SOHN, and DONG JOON MIN
}

\begin{abstract}
An investigation was carried out to study the heat-transfer phenomena across mold flux film by using infrared emitter technique (IET). With IET, it is possible to develop the mold fluxes with a liquid layer at the top and a solid layer in contact with copper mold with the degree of varying crystallization. The dynamic crystallization and melting process of the mold fluxes as well as their effects on the overall heat-transfer rate in the mold were successfully conducted. The single hot thermocouple technique (SHTT) was also employed in this investigation to study the melting and crystallization behaviors of mold fluxes for the interpretation of IET results. The results suggested that the interfacial thermal resistance between the solidified mold flux and copper mold would significantly influence the heat-transfer rate in continuous casting and the melting of the mold flux tends to enhance the overall heat-transfer rate. The technique established in this article by utilizing the IET can be well applied to the investigation of mold flux thermal properties, which in turn gives guidelines for the design of new mold flux for continuous casting.
\end{abstract}

DOI: $10.1007 / \mathrm{s} 11663-012-9718-3$

(C) The Minerals, Metals \& Materials Society and ASM International 2012

\section{INTRODUCTION}

MOLD powders are fluxing agents adopted as raw materials in continuous casting of steel, and normally consisted of $\mathrm{CaO}, \mathrm{SiO}_{2}, \mathrm{Na}_{2} \mathrm{O}$, and $\mathrm{CaF}_{2}$ along with minor additions of other mineral oxides. ${ }^{[1]}$ It plays important roles in the continuous casting with a variety of functions, such as lubricating the strand, adsorbing inclusions, adjusting heat transfer between the mold and steel shell, and insulating the molten steel from oxidation. ${ }^{[2]}$ Thus, the mold fluxes strongly affect the final surface quality of the slab and involve with the formation of casting defects, such as longitudinal cracking, star cracking, oscillation marks, mold wear, and breakouts. ${ }^{[3]}$

During continuous casting, the liquid mold flux infiltrates into the shell/mold gap and solidifies on the water-cooled copper mold forming complex amorphous and crystalline structures due to the large temperature gradient distribution between the steel shell and copper mold. ${ }^{[4]}$ The mold flux is usually composed of two to three layers, depending upon the cooling rate and its chemical compositions, i.e., a liquid layer next to the steel shell, a solid glassy layer against the mold wall, and

KEZHUAN GU and JUAN WEI, Graduate Students, and WANLIN WANG, Professor, are with the School of Metallurgical Science and Engineering, Central South University, Changsha 410083, P.R. China. Contact e-mail: wanlin.wang@gmail.com HIROYUKI MATSUURA, Associate Professor, and FUMITAKA TSUKIHASHI, Professor, are with the Department of Advanced Materials Science, Graduate School of Frontier Sciences, The University of Tokyo, Kashiwa, Chiba 277-8561, Japan. IL SOHN, Associate Professor, and DONG JOON MIN, Professor, are with Materials Science and Engineering, Yonsei University, Seoul 120-749, Korea.

Manuscript submitted April 6, 2012

Article published online September 18, 2012. a crystallized layer in between, or sometimes just a liquid and a solid crystalline layer. ${ }^{[5,6]}$ The liquid slag film provides lubrication to the shell, ${ }^{[7]}$ while the partially crystallized slag film can reduce the heat-transfer rate by scattering radiation and forming the air gaps at the interface between the solid mold flux and copper mold. ${ }^{[8,9]}$ Therefore, understanding of the melting and crystallization behaviors of mold flux and its effect on heat-transfer rate is essential during continuous casting.

Regarding the crystallization of mold flux, a number of techniques has been developed to measure the crystals growth rate and the crystallinity of mold flux, which include the differential thermal analysis (DTA), ${ }^{[10]}$ hot stage microscopy such as confocal scanning laser microscopy (CLSM), ${ }^{11,12]}$ and single hot thermocouple technique (SHTT) or double hot thermocouple technique (DHTT). ${ }^{[13,14]}$ These techniques can be used to measure the crystallization properties of mold flux by developing time-temperature-transformation (TTT) or continuouscooling-transformation (CCT) diagrams. Meanwhile, Susa et al. ${ }^{[9]}$ and Diao et al. ${ }^{[15]}$ studied the effect of crystallization on heat-transfer rate by measuring the radiative properties, such as the absorption and extinction coefficient using a spectrophotometer. However, a quantitative analysis on the effect of dynamic crystallization and melting on heat-transfer rate has yet to be fully determined. This has led to the development of heat flux simulators that mimic the conditions of mold flux melting and the crystallization in continuous casting.

Shibata et al. ${ }^{[16]}$ studied the overall thermal resistance by pouring the molten slag onto the copper mold and measuring transient heat transfer to the mold; however, it cannot be used to investigate the steady-state heat flux. Yamauchi et al. ${ }^{[8]}$ and Cho et al. ${ }^{[17]}$ developed a mold simulator with a parallel-sided plate filled with 
mold flux to study the heat-transfer phenomenon by measuring the steady-state one-dimensional heat flux; however, it lacks the information about transient heat transfer and is difficult to control one-dimensional heat transfer. Wen et al. ${ }^{[18]}$ developed a copper finger dipping method to study the heat transfer across mold flux by measuring the temperature difference of inlet and outlet water flow in copper mold, but it cannot control the thickness of slag film readily and is unable to detect the transient heat-transfer changes in the mold.

In this study, an infrared emitter ${ }^{[19,20]}$ was used to investigate the heat-transfer phenomena across mold flux disks. By using this technique, the mold slag films with different chemical compositions were exposed to the heat flux that is similar to the real caster, and their thermal properties were studied under the controlled conditions. The research in this article was carried out in the following ways: First, the infrared emitter irradiates the surface of a copper mold that was covered with a solid glassy mold flux disk; then, the responding in-mold heat flux was analyzed by the response of the subsurface mold temperatures. Meanwhile, the experiments were recorded by a digital camcorder to investigate the crystallization and the melting behaviors of the mold fluxes. The SHTT was also employed in this article to simulate the mold fluxes melting and crystallization behaviors during IET experiments. Finally, the results from both infrared emitter technique (IET) and SHTT were discussed.

\section{EXPERIMENTAL APPARATUS AND PROCEDURES}

\section{A. Heat-Transfer Simulator}

A schematic of the experimental apparatus was shown in Figure 1, the details of which have been described elsewhere. ${ }^{[19]}$ The experimental apparatus mainly included a power controller, an infrared radiant heater capable of emitting $2.0 \mathrm{MW} / \mathrm{m}^{2}$ heat flux at the rate of 380 voltages, a data acquisition system, and a command-and-control unit. The intensity of the incident energy could be controlled precisely by changing the voltage applied to the heating elements through a silicon-controlled rectifier (SCR)-based power controller. The wave length of IET was in the range of 0.7 to 8 micron with a peak of 1.2 micron, which was similar to that from the solidifying shell during the continuouscasting process as other research indicated. ${ }^{[21]}$

The copper mold was simulated by a one-end watercooled copper cylinder, which acted as the radiation target, and its schematic figure was shown in Figure 2. As the heat flux was applied to the top surface of the copper mold, which was covered with mold flux disk, the response temperatures could be measured by the subsurface thermocouples. Thus, the absorbed heat flux passing through copper mold was computed with the measured temperature gradient inside the mold. In order to ensure the heat transfer across the flux disk to the mold is one dimensional, the mold system was insulated with thick wood.

\section{B. Mold Flux Disk Preparation}

Three types of commercial mold powder were studied in this paper, and their main chemical compositions after premelting were listed in Table I. As reported in our earlier study, ${ }^{[5]}$ the evaporative loss of volatile fluoride is not significant. The mold fluxes were decarburized by placing them into a programmable furnace prior to the fusion process. Then, the decarburized mold flux was melted at $1723 \mathrm{~K}\left(1500{ }^{\circ} \mathrm{C}\right)$ in a graphite crucible placed in a resistance furnace for 300 seconds and then quenched from its molten state onto a stainless steel plate at room temperature to achieve a fully glass phase. A new cylindrical, tube-like copper mold with the

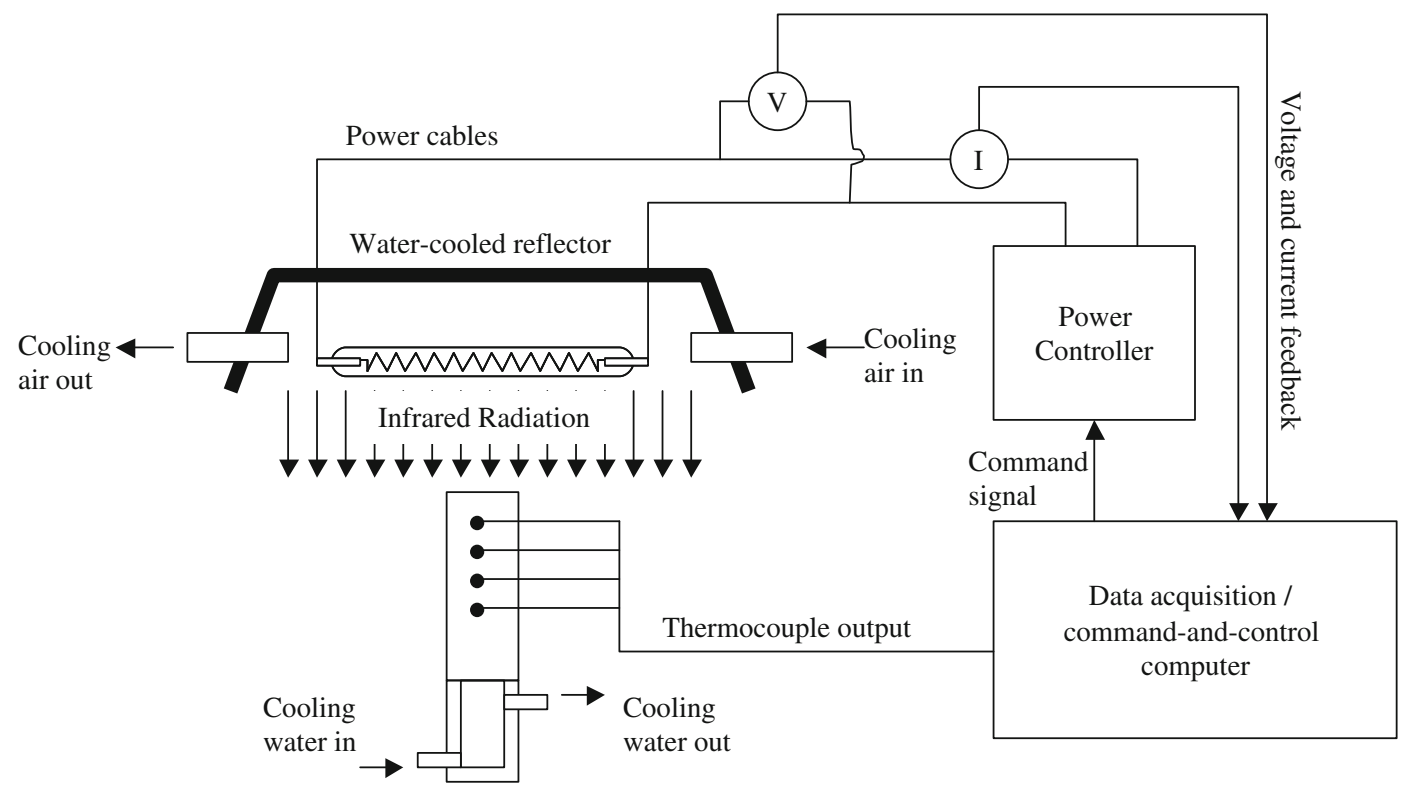

Fig. 1-Schematic illustration of the infrared emitter. 
same diameter as the copper substrate in IET tests was used to cast the mold flux before it solidified on the steel. The mold flux disks were then polished with the $\mathrm{SiC}$ sandpapers down to 1200 (grit size) to control its surface roughness and thickness. The polished glassy samples were then placed on the top of the copper mold individually for heat-transfer experiments.

A small amount of solidified glassy mold flux was also crushed and ground into powders for SHTT tests.

\section{Experimental Procedure of IET Tests}

Figure 3 shows the heating profile employed in the IET experiments. The copper system with individual

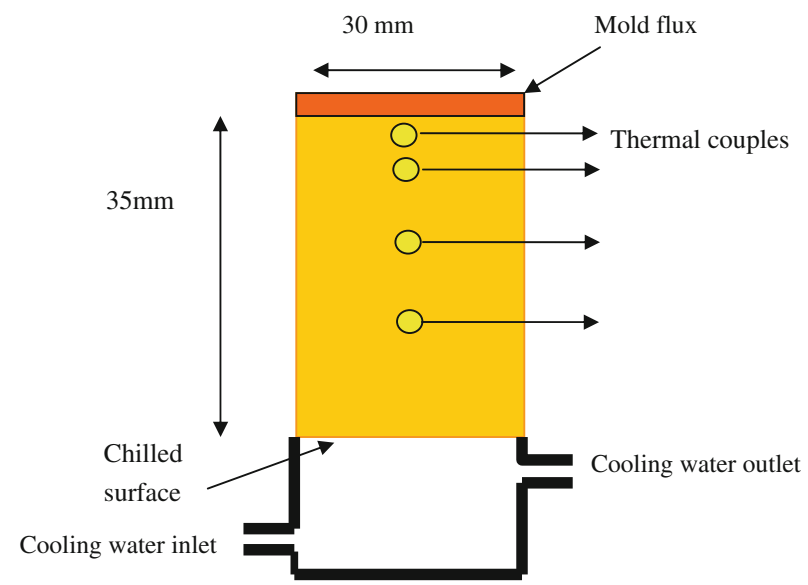

Fig. 2-Schematic figure of copper substrate used as the radiation target.

Table I. The Chemical Compositions of Commercial Mold Fluxes (in Mass Pet)

\begin{tabular}{lccccccc}
\hline & $\mathrm{CaO}$ & $\mathrm{SiO}_{2}$ & $\mathrm{Al}_{2} \mathrm{O}_{3}$ & $\mathrm{MgO}$ & $\mathrm{F}$ & $\mathrm{Na}_{2} \mathrm{O}$ & $\mathrm{R}$ \\
\hline Flux 1 & 33.53 & 42.05 & 7.02 & 2.00 & 5.87 & 9.03 & 0.8 \\
Flux 2 & 41.18 & 34.32 & 6.92 & 2.08 & 5.95 & 9.05 & 1.2 \\
Flux 3 & 44.78 & 35.22 & 8.04 & 1.96 & 3.48 & 6.02 & 1.27 \\
\hline
\end{tabular}

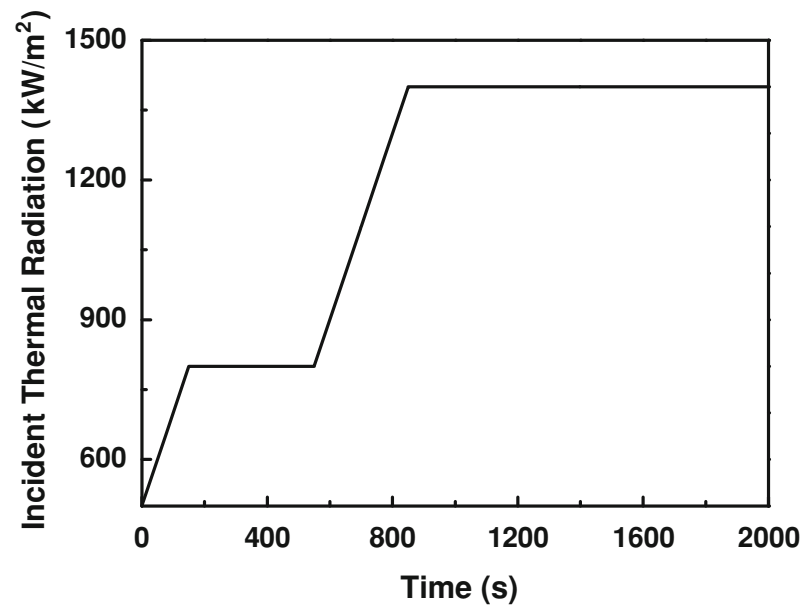

Fig. 3-The heating profile for IET experiments. glassy disk was first preheated with a $500 \mathrm{~kW} / \mathrm{m}^{2}$ thermal energy, and then the incident thermal energy was increased linearly at the rate of $2 \mathrm{~kW} / \mathrm{m}^{2} \mathrm{~s}$ to a constant $800 \mathrm{~kW} / \mathrm{m}^{2}$ and maintained for 400 seconds. After that, the incident heat flux was increased to a constant $1400 \mathrm{~kW} / \mathrm{m}^{2}$ and maintained for 1200 seconds.

Figure 4 shows the subsurface response temperatures when the above heating profile was applied to a bare copper mold system. The thermocouples placed at 2, 5, 10 , and $18 \mathrm{~mm}$ below the irradiated surface (Figure 2) were recorded as $T_{1}, T_{2}, T_{3}$, and $T_{4}$, respectively. The cooling water inlet and outlet temperatures were also recorded as $T_{\text {in }}$ and $T_{\text {out }}$. The system reached steady state in 100 to 200 seconds. As the thermal properties are functions of temperature and time, the 1-dimensional inverse heat conduction developed by Beck, ${ }^{[22]}$ which is sufficient to use only one internal body temperature and one boundary condition to determine the unknown boundary condition ${ }^{[23]}$ and estimate the heat flux by utilizing measured transient interior temperatures, is adapted

$$
\frac{\partial}{\partial \mathrm{x}}\left(k \frac{\partial T_{i}}{\partial x}\right)=\left(\rho c_{\mathrm{p}}\right) \frac{\partial T_{i}}{\partial t}
$$

where $x$ is the distance below the top surface, $k$ is thermal conductivity, $T$ is absolute temperature, $\rho$ is the mass density of copper, $t$ is time, and $c_{\mathrm{p}}$ is the copper heat capacity.

The measured heat flux histories corresponding to Figure 4 were given in Figure 5, and it could be observed that the measured heat flux was first increased linearly with the addition of the output power, and then it came into a steady state in a very short time.

\section{SHTT Tests for Mold Fluxes}

The SHTT was adopted here for the study of melting and crystallization behaviors of mold flux, and its schematic illustration was shown in Figure 6. The principle of the SHTT has been described in detail elsewhere. ${ }^{[14]}$ Figure 7 shows the experimental thermal profile for the melting and cooling measurements. About

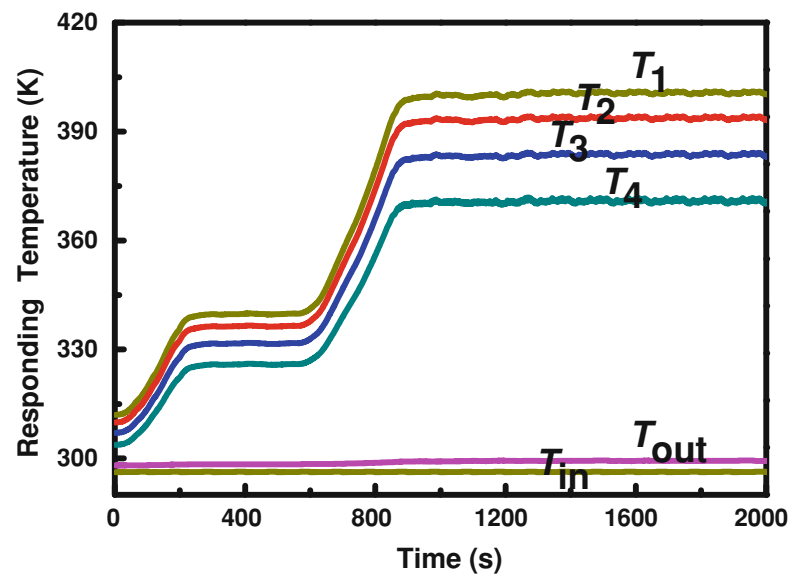

Fig. 4-The in-mold responding temperatures history for bare copper system. 
$10 \mathrm{mg}$ mold power was mounted on the tip of a B type thermocouple and heated to $1723 \mathrm{~K}\left(1500{ }^{\circ} \mathrm{C}\right)$ at a heat rate of $293 \mathrm{~K}\left(20^{\circ} \mathrm{C}\right) / \mathrm{s}$. It was held for 300 seconds to eliminate the bubbles and homogenize its chemical composition. After that, for the process in Figure 7(a),

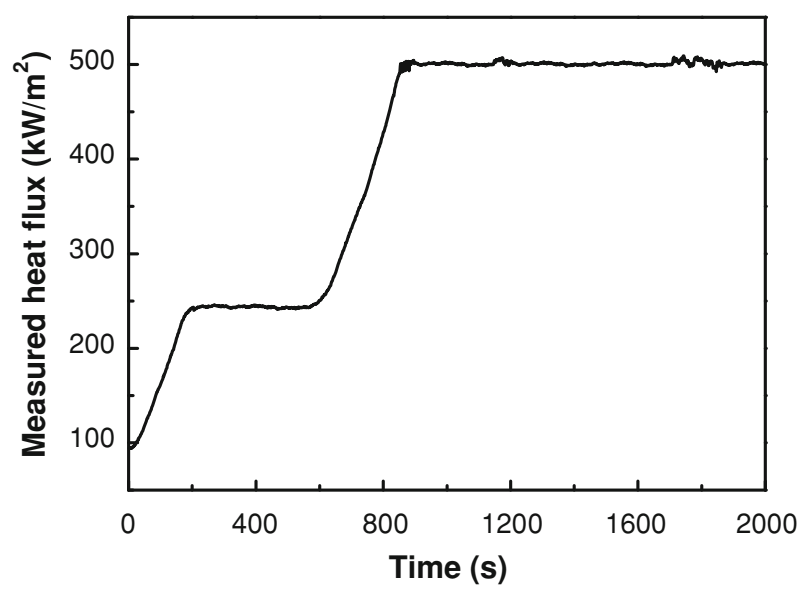

Fig. 5-The measured heat flux history for bare copper system.

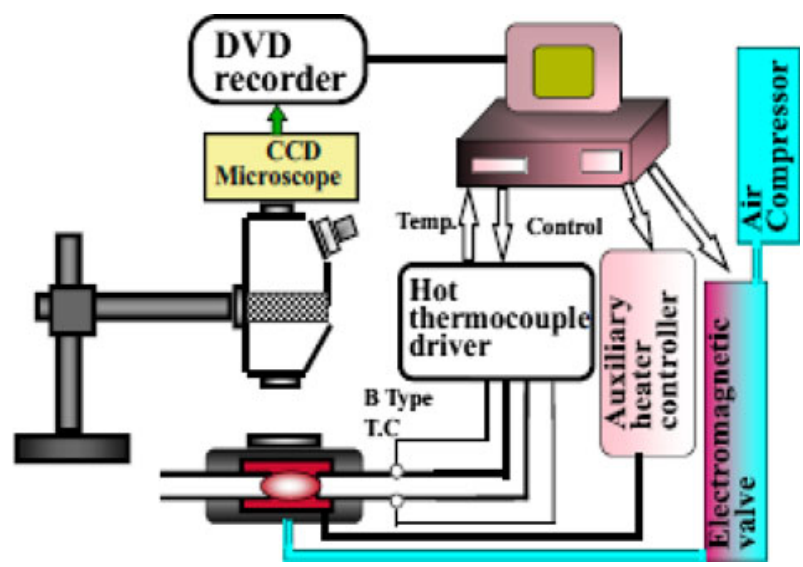

Fig. 6-The experimental apparatus for DHTT.

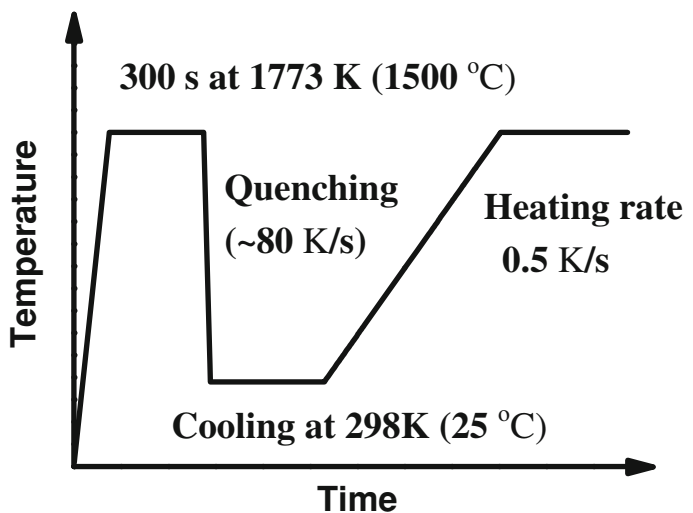

(a) the mold flux was cooled down rapidly at a cooling rate of $353 \mathrm{~K}\left(80^{\circ} \mathrm{C}\right) / \mathrm{s}$ to room temperature to achieve glassy phase. Then, the glassy mold flux was heated at a rate of $273.5 \mathrm{~K}\left(0.5^{\circ} \mathrm{C}\right) / \mathrm{s}$ to simulate the crystallization behaviors of IET tests (from stage I to stage V, Section III-A). For the process in Figure 7(b), after holding at $1773 \mathrm{~K}$ $\left(1500{ }^{\circ} \mathrm{C}\right)$, the molten flux was cooled at a rate of $274 \mathrm{~K}$ $\left(1{ }^{\circ} \mathrm{C}\right) / \mathrm{s}$ to study the molten slag solidification behavior during the continuous-cooling process.

\section{RESULTS AND DISCUSSION}

\section{A. The In Situ Observation of Heat Transfer Across Mold Fluxes}

Three 4.0- mm-thick glass disks with different chemical compositions as shown in Table I were placed on the copper mold individually and preheated by a 500$\mathrm{kW} / \mathrm{m}^{2}$ thermal heating. Then, they were subjected to the thermal heating according to Figure 3. The whole experiment process was recorded by a digital camcorder to study the mold flux crystallization and melting behavior, and their responding in-mold heat fluxes were then calculated and shown in Figure 8.

There are eight stages appearing in the responding heat flux histories for fluxes 1 and 2. Stage I is a period during which the heat flux increases linearly with the addition of thermal heating; stage II is the time of the initiation of heat flux deviation (due to the mold flux crystallization); stage III is a further attenuation of heat flux stage where the heat flux continues to reduce due to the further crystallization; stage IV is the period of steady state when the crystallization is completed and heat flux keeps constant; stage $\mathrm{V}$ is the period of heat flux increasing linearly with the incident energy; stage VI is the time of the heat flux deviation due to the mold flux melting; stage VII is a stage where the heat flux continues to increase due to the mold flux further melting under constant thermal heating; and stage VIII is the period of steady state when the crystallization and melting is completed and overall heat flux keeps constant. The summary of the each stage was given in Table II.

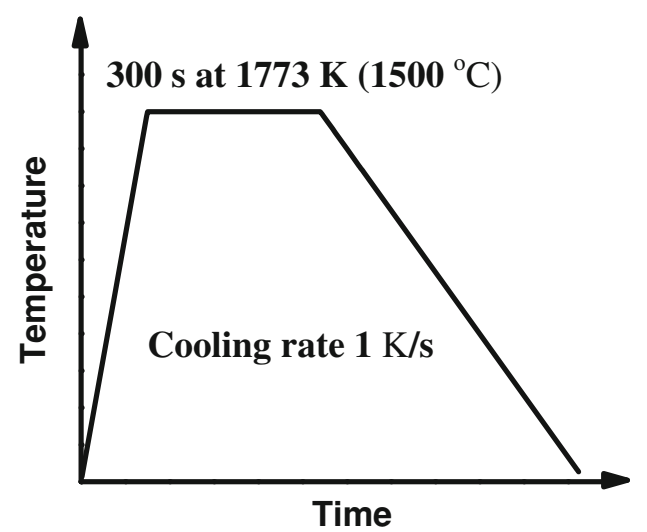

(b)

Fig. 7-Thermal cycle for study of melting and crystallization behaviors of mold fluxes $(a)$ crystallization process and $(b)$ air cooling process. 


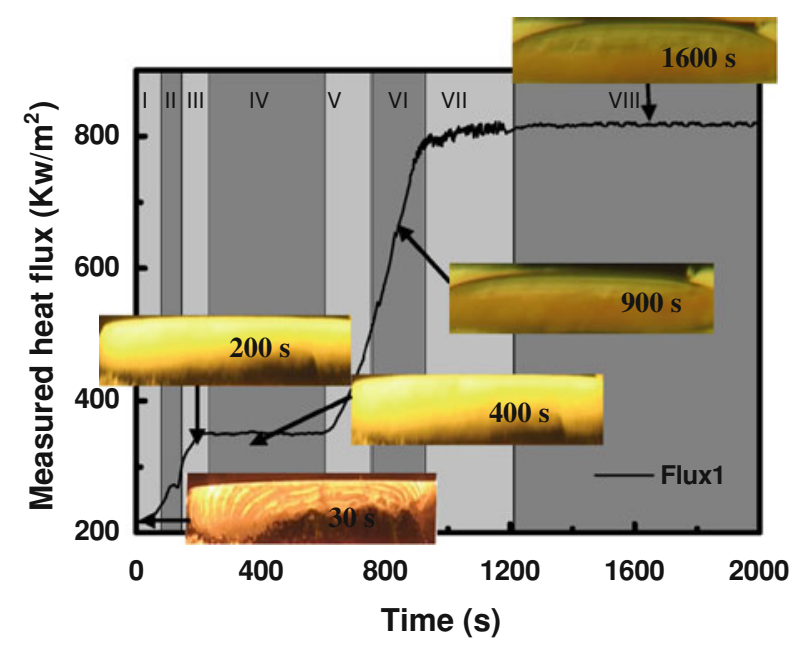

(a)

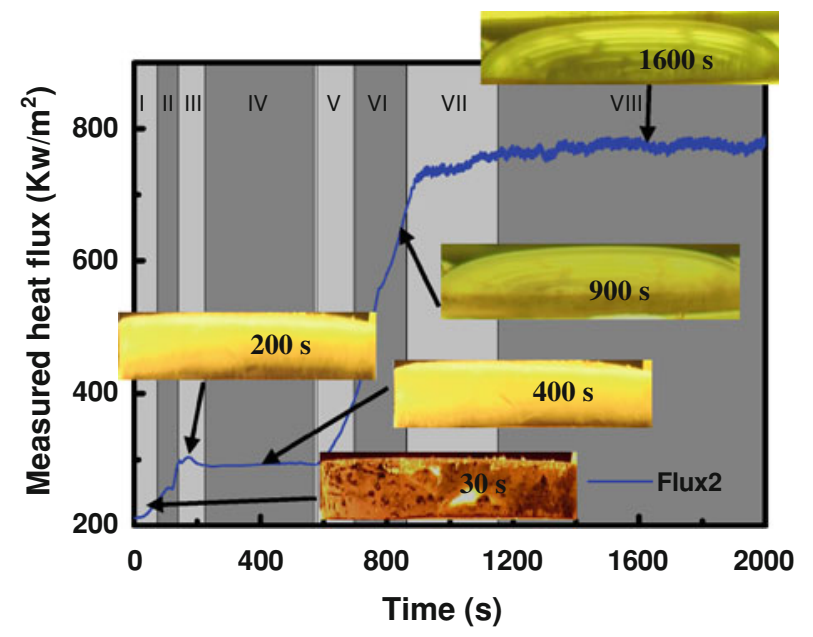

(b)

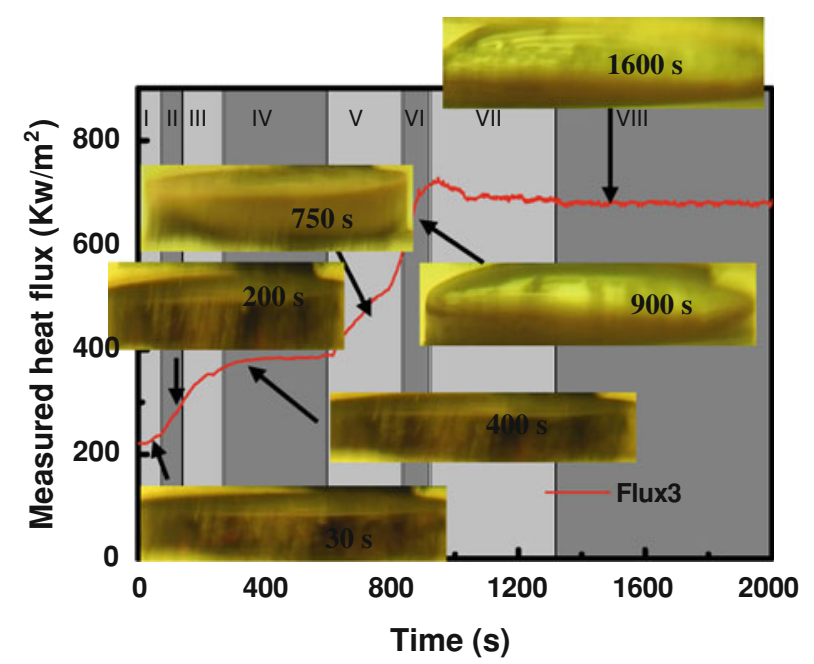

(c)

Fig. 8-The measured heat flux history for different mold fluxes: $(a)$ flux $1,(b)$ flux 2 , and (c) flux 3 .

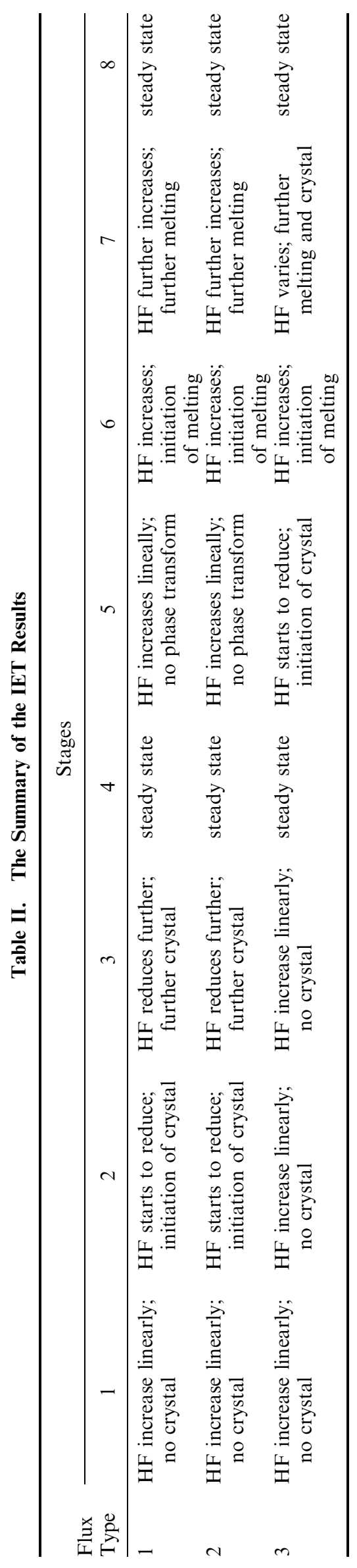

VOLUME 43B, DECEMBER 2012-1397 
The images corresponding to each stage were also shown in Figure 8. From the digital images, it was clearly observed that glassy films of flux 1 and flux 2 are partially crystallized at stage II with the increase of the incident energy, then get further crystallized (stage III) and step into a relatively constant state (stage IV), which is consistent with our previous observations. ${ }^{[24]}$ Then, with the further addition of incident energy, the disk top surface temperature is getting higher and the melting/ crystal dissolution are initiated at the top surface as shown in the picture at stage VI. With longer annealing time, the molten layer moves down and leads to a larger reduction of the crystal volume at stage VII. Finally, the system comes to stage VIII, where the heat flux becomes stable and the thickness of the liquid layer and solid layers are fixed.

However, flux 3 continues to be glassy during stages I through IV, which is different from flux 1 and flux 2. This seems to correspond to the higher crystallization temperature of flux 3 (approximately $1294 \mathrm{~K}\left[1021^{\circ} \mathrm{C}\right]$ ) compared with flux 1 (approximately $1190 \mathrm{~K}\left[917{ }^{\circ} \mathrm{C}\right]$ ) and flux 2 (approximately $1174 \mathrm{~K}\left[901{ }^{\circ} \mathrm{C}\right]$ ), which will be explained in the Section III-D. When the incident power was increased to $1 \mathrm{MW} / \mathrm{m}^{2}$ at stage $\mathrm{V}$, the crystallization is initiated at the top and developed quickly toward the bottom. With the improvement of the flux 3 film top surface temperature and the incident power, the melting of the mold flux is then initiated at stage VI. Finally, the system steps into a final steady state at stage VIII.

\section{B. Effect of Mold Flux Layers Variation on Heat- Transfer Rate}

In order to study the effect of mold flux layers variation on the heat-transfer rate, the measured heat fluxes and the final cross-section views corresponding to each flux disk were given in Figure 9. It could be observed that the measured heat fluxes for each mold flux at first steady state (stage IV) are around 386 (flux 3), 348 (flux 1), and 295 (flux 2) $\mathrm{kW} / \mathrm{m}^{2}$, respectively, where flux 3 is still glassy with the highest heat-transfer rate and flux 2 is fully crystallized corresponding to the lowest heat-transfer rate. Compared with the steadystate heat flux (stage IV) for bare copper system $250 \mathrm{~kW} / \mathrm{m}^{2}$, the system with mold flux would definitely enhance the radiative heat-transfer as suggested in our previous study. ${ }^{[25]}$ Therefore, it could be concluded that the glassy phase can absorb radiation gradually as it travels through the medium but does not scatter radiation appreciably due to the amorphous structure. ${ }^{[26]}$ However, there would be more incident radiation reflected and scattered from the crystals surface, grain boundary, and defects, such that there would be less energy absorbed and conducted to the mold.

At stage VIII, where all the mold fluxes are finally formed a liquid layer and a solid layer (mixture of glass and crystals for flux 1 and only crystals for flux 2, flux 3) under the thermal heat flux of $1.4 \mathrm{MW} / \mathrm{m}^{2}$ that is similar to the real caster, the measured steady-state heat fluxes are around $819 \mathrm{~kW} / \mathrm{m}^{2}$ for flux $1,777 \mathrm{~kW} / \mathrm{m}^{2}$ for flux 2 and $676 \mathrm{~kW} / \mathrm{m}^{2}$ for flux 3 , respectively. The images of the three samples after the experiments were shown in the Figure 9, and it was found that the structure of mold fluxes with the different layers has an important effect on overall heat-transfer rate. As shown in Figure 9, the bottom surface of flux 1 is keeping glassy, while flux 2 and flux 3 are completely crystallized, such that their surfaces would become rougher than that of flux 1, and it leads to a larger interfacial thermal resistance for flux 2 and flux 3. The interfacial thermal resistances for above mold fluxes $R_{\text {int }}$ were calculated in Section III-E,

Table III. Thickness of Each Layer for Different Mold Fluxes

\begin{tabular}{lccc}
\hline & Flux 1 & Flux 2 & Flux 3 \\
\hline Total thickness $(\mathrm{mm})$ & 4.00 & 4.00 & 4.00 \\
Liquid $(\mathrm{mm})$ & 1.37 & 2.48 & 1.88 \\
Crystalline $(\mathrm{mm})$ & 2.30 & 1.52 & 2.12 \\
Glassy $(\mathrm{mm})$ & 0.33 & 0 & 0 \\
\hline
\end{tabular}

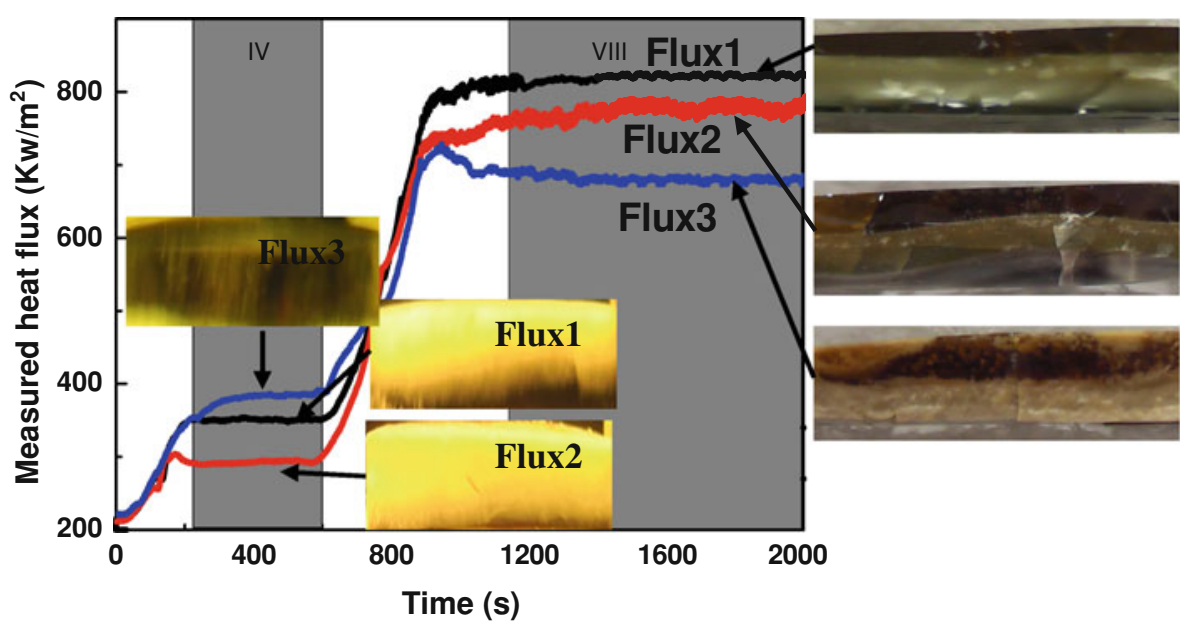

Fig. 9-The measured heat fluxes histories for different mold fluxes: (a) flux 1 at stage II (right) and stage VI (left), (b) flux 2 at stage II (right) and stage VI (left), (c) flux 3 at stage II (right) and stages V and VI (left) (d). 
and they are $7.6 \times 10^{-4} \mathrm{~m}^{2} \mathrm{~K} / \mathrm{W}$ (flux 1), $10.3 \times 10^{-4}$ (flux 2), and $12.6 \times 10^{-4} \mathrm{~m}^{2} \mathrm{~K} / \mathrm{W}$ (flux 3), respectively. The thicknesses of each layer for different mold fluxes were also measured and shown in Table III. With the lower interfacial thermal resistance due to the glassy bottom slag/mold interface, the steady-state heat flux of
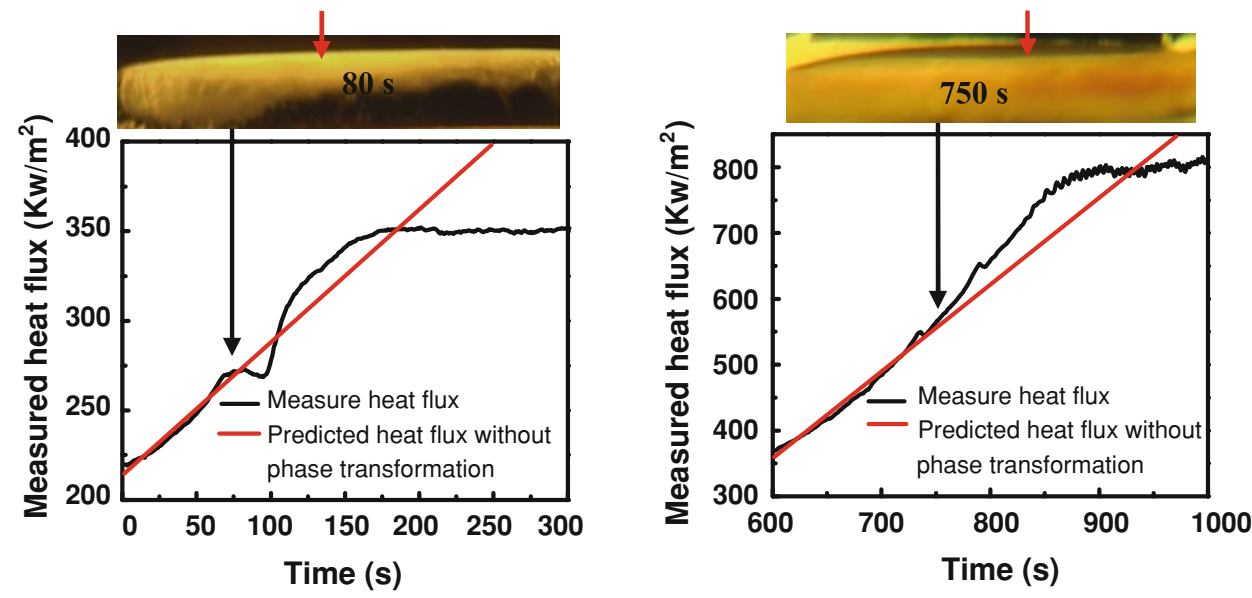

(a) Flux 1 at stage II (right) and stage VI (left)
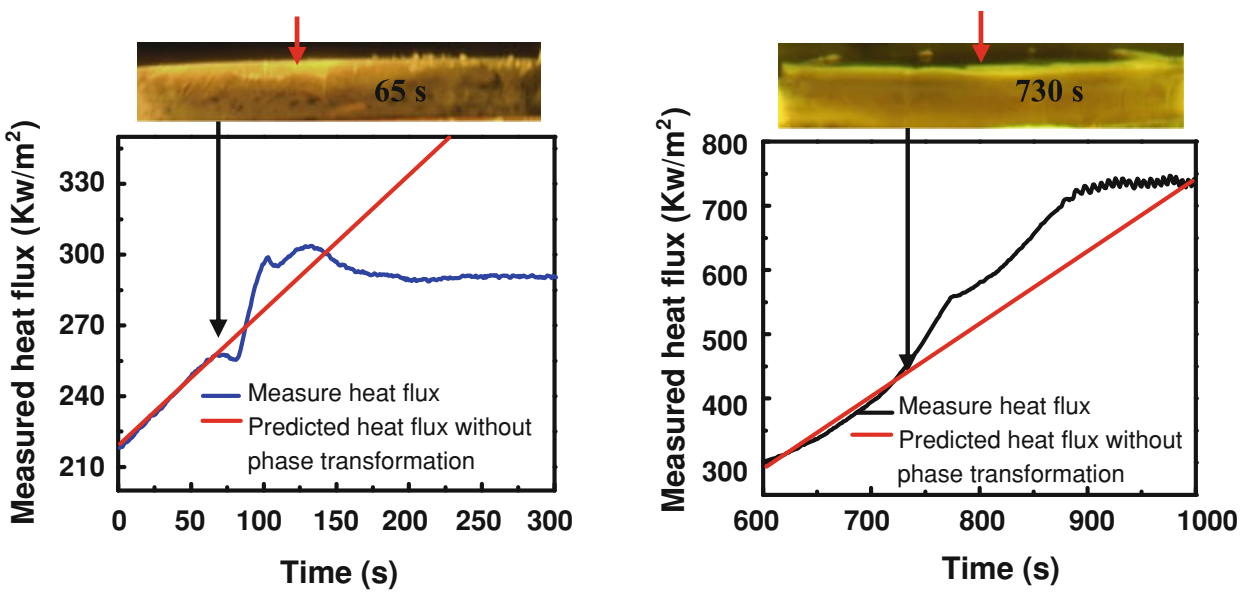

(b) Flux2 at stage II (right) and stage VI (left)
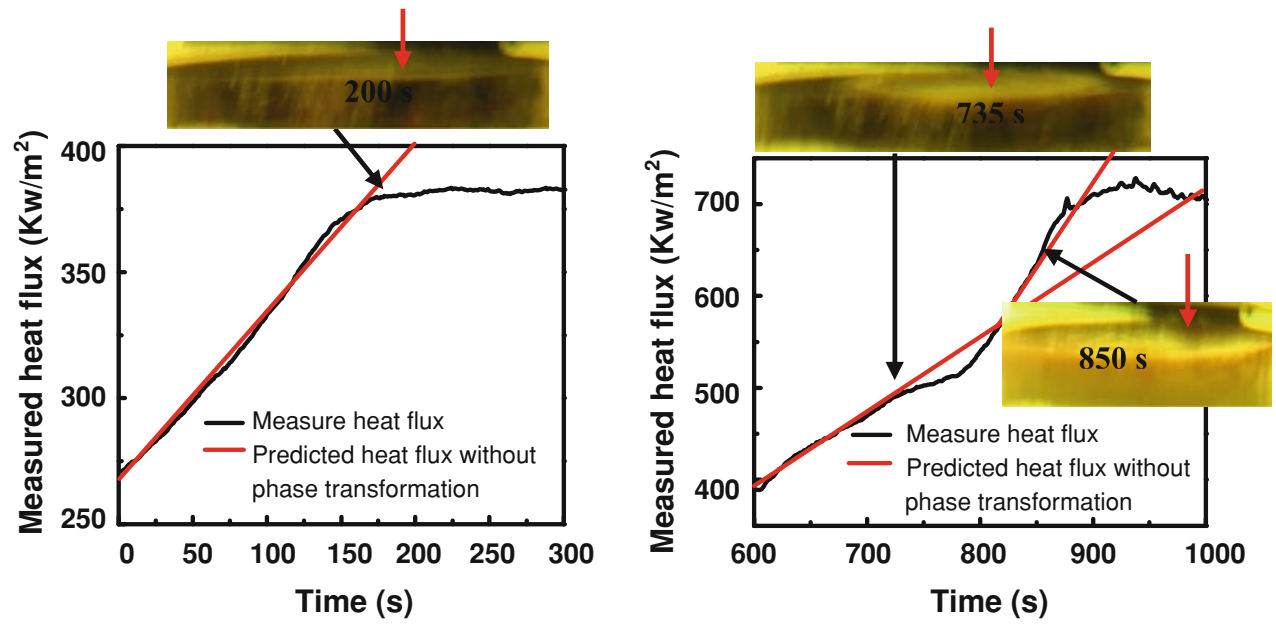

(c) Flux3 at stage II (right) and stage V-VI (left)

Fig. 10-The measured heat fluxes for the three mold fluxes systems during the heating period of stage 1 and stage V: (a) flux 1 , (b) flux 2, and (c) flux 3. 


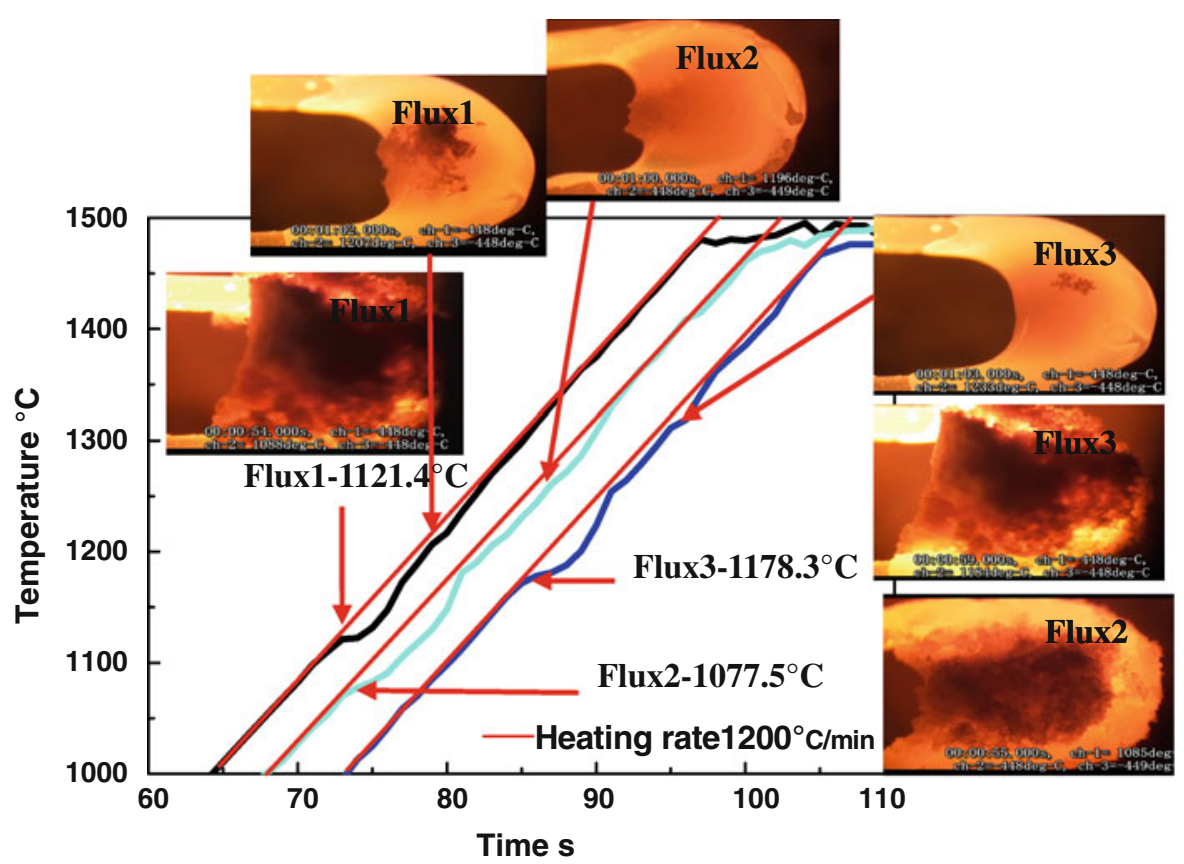

Fig. 11-Melting behaviors for the three mold fluxes.

flux 1 at stage VIII is higher than flux 2 and flux 3 . The results are consistent with previous studies ${ }^{[6,17,24]}$ that the interfacial thermal resistance is the dominant factor affecting the heat-transfer between the strand and mold.

As for flux 2 that with a thicker liquid layer (Table III) and a lower thermal interfacial resistance, its responding heat flux is higher than flux 3. Therefore, the enhanced molten layer of mold flux would increase the total heat-transfer rate. ${ }^{[26]}$

\section{The Crystallization and Melting Behaviors of Different Mold Fluxes}

In order to study the behaviors of mold fluxes crystallization, melting, and crystal fraction dissolution, the responding heat fluxes during the initial crystallization and melting at stages I, II, and VI were shown in Figure 10, where the output heating thermal flux was first increasing from $500 \mathrm{~kW} / \mathrm{m}^{2}$ to $800 \mathrm{~kW} / \mathrm{m}^{2}$ and then from $800 \mathrm{~kW} / \mathrm{m}^{2}$ to $1400 \mathrm{~kW} / \mathrm{m}^{2}$ with a rate of $2 \mathrm{~kW} / \mathrm{m}^{2} \mathrm{~s}$.

During stage II, it could be seen that there is a clear deviation of the heat flux curve occurring at 80 seconds for flux 1 and 65 seconds for flux 2, while no deviation was observed for flux 3 . The slag pictures corresponding to each specific time where the heat flux starts to deviate were captured and shown in Figure 10, where the opaque crystals are clearly shown at the top of the flux 1 and flux 2, while flux 3 is still keeping glassy. The heat fluxes at the deviation point at stage II for flux 1 and flux 2 tend to reduce, which approves that the mold flux crystallization inhibition radiation in continuous casting. During stage VI, the deviation of the heat flux curve is also detected at 750 seconds for flux 1 and $730 \mathrm{sec}-$ onds for flux 2. Similarly, the slag images corresponding to the specific times were shown in Figure 10, where the transparent liquids are clearly observed at the top of the disks of flux 1 and flux 2. The deviation curves here suggest the melting of slag enhances the overall heattransfer rate. The initial deviation of heat flux for flux 3 is at 735 seconds, and the second deviation occurs at 850 seconds as shown in Figure 10(c).

\section{Study of Crystallization and Melting Behavior for Different Mold Fluxes Through Single Hot Thermocouple Technique}

In order to further study the melting and crystallization behaviors of mold fluxes, the SHTT was employed in this article. Figure 11 shows the melting behaviors of those three mold fluxes when they were heated according to Figure 7(a), and their images during melting period were also provided. It can be seen there is a deviation occurring during the heating period, which is at $1394.4 \mathrm{~K}\left(1121.4{ }^{\circ} \mathrm{C}\right)$ for flux $1,1350.5 \mathrm{~K}\left(1077.5^{\circ} \mathrm{C}\right)$ for flux 2, and $1451.3 \mathrm{~K}\left(1178.3{ }^{\circ} \mathrm{C}\right)$ for flux 3 . These are determined as the initial melting points of above mold fluxes. As the flux 3 owns the highest initial melting temperature, it will take the longest time to start the flux melting, which is consistent with the observation of IET test measurement as shown at stage VI in Figure 10(c).

Figure 12 shows the mold fluxes crystallization behaviors at a continuous heating period (Figure 7(a)), which simulates the crystallization processes of fluxes (for flux 1 and flux 2, it is stages I through III, and it is stages V and VI for flux 3) during IET experiments. The in situ observations show that the initial crystallization (glass transformation) temperatures for flux 1, flux 2, and flux 3 were approximately $1190 \mathrm{~K}, 1174 \mathrm{~K}$, and $1294 \mathrm{~K}\left(917{ }^{\circ} \mathrm{C}, 901{ }^{\circ} \mathrm{C}\right.$, and $\left.1021{ }^{\circ} \mathrm{C}\right)$, respectively, where the 5 vol pct of crystallization was defined as the beginning of crystallization. ${ }^{[14]}$ Therefore, it explained 

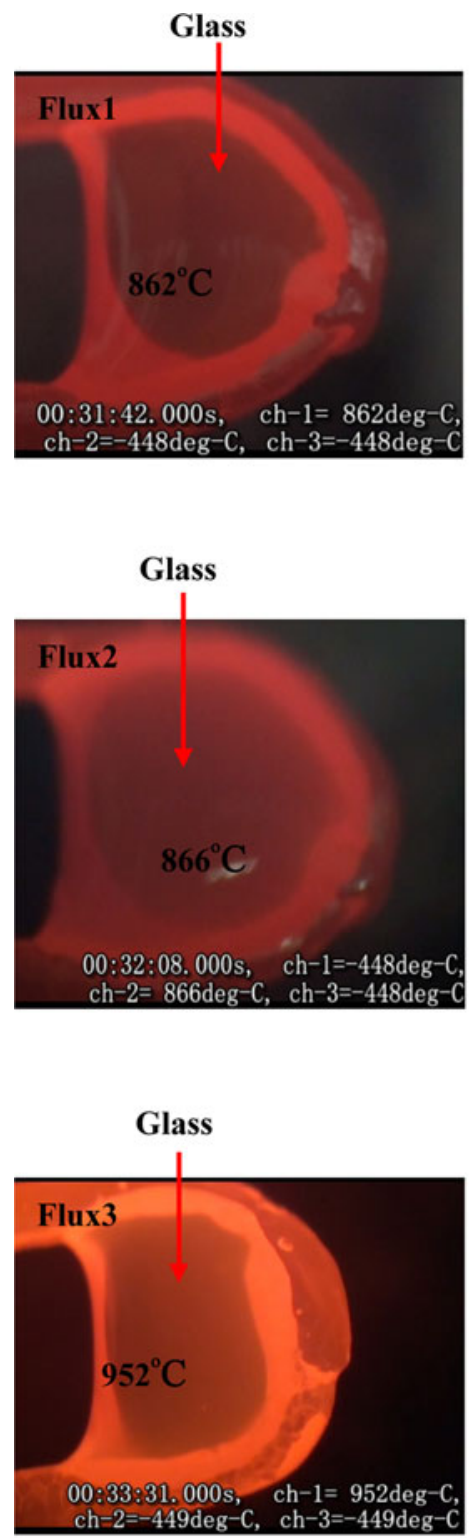

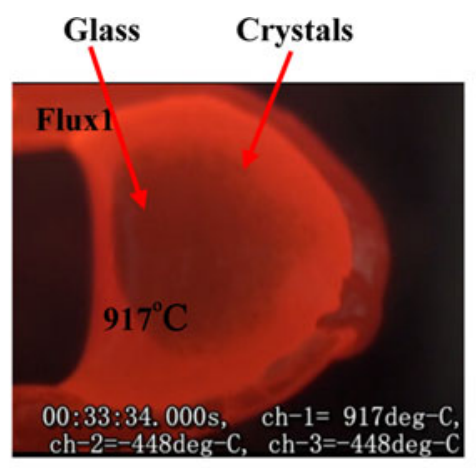

(a)
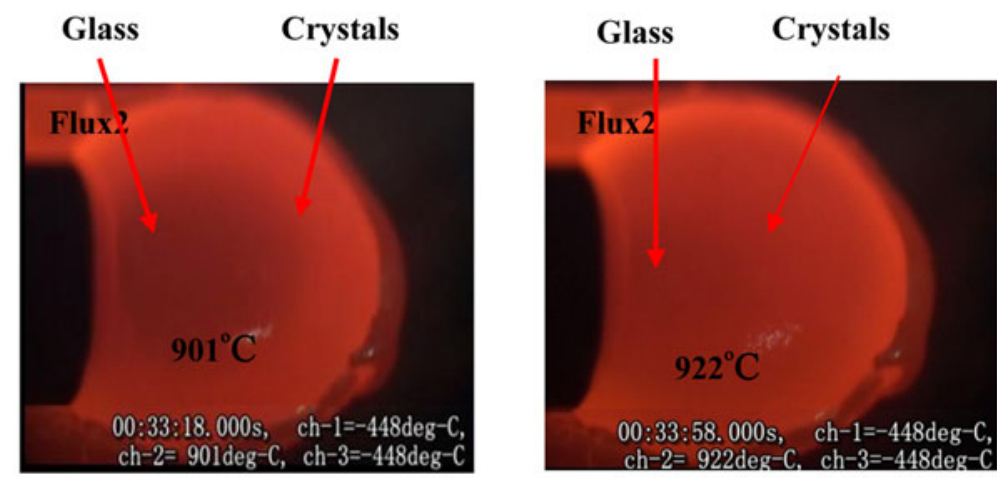

(b)
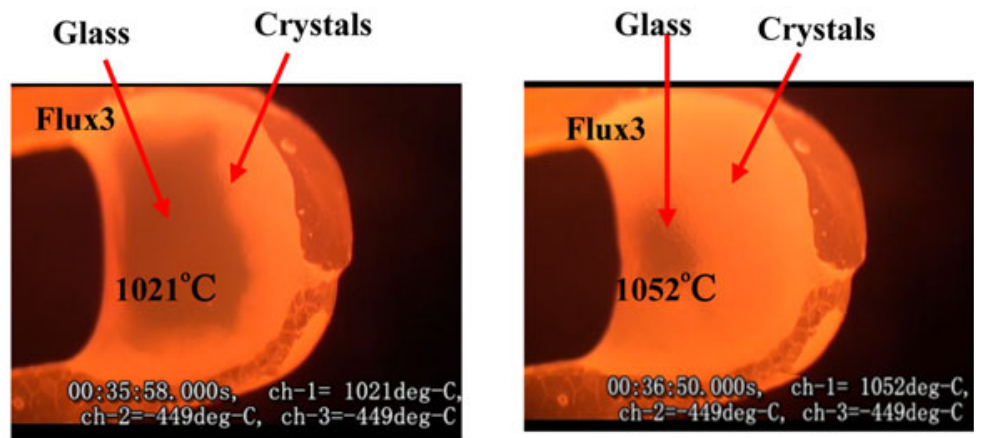

(c)

Fig. 12-Crystallization behavior of mold fluxes at continuous heating period: (a) flux 1, (b) flux 2, and (c) flux 3 .

the different crystallization phenomena during the IET experiments as shown in Figure 10.

Figure 13 shows the solidification behaviors of the molten mold fluxes during continuous-cooling period (Figure 7(b)). It can be seen that the flux 3 is initially crystallized at a higher temperature $1662 \mathrm{~K}\left(1389^{\circ} \mathrm{C}\right)$, while flux 1 and flux 2 are crystallized at $1359 \mathrm{~K}$ and $1564 \mathrm{~K}\left(1086{ }^{\circ} \mathrm{C}\right.$ and $\left.1291^{\circ} \mathrm{C}\right)$, respectively.

\section{E. Study of the Interfacial Thermal Resistance Between} the Copper Mold and Mold Flux

A numerical calculation was conducted to study the interfacial thermal resistance between the copper mold and the solidified mold flux film. Here, it was assumed that ${ }^{[9,24]}(1)$ heat is transferred in one direction from the mold fluxes to the copper mold; and(2) the total heat flux is consisted of radiative and conductive heat flux.

Therefore, the total heat flux $q_{\text {tot }}$ through the mold flux film can be expressed as Eq. [2]

$$
q_{\mathrm{tot}}=q_{\mathrm{rad}}+q_{\mathrm{cond}}
$$

The conductive and radiative heat flux at steady state through solid mold flux layer can be rewritten as Eqs. [3] and [4]

$$
\begin{aligned}
q_{\mathrm{cond}} & =K_{\mathrm{cond}} \frac{T_{1}-T_{2}}{d} \\
q_{\mathrm{rad}} & =K_{\mathrm{rad}} \frac{T_{1}-T_{2}}{d}
\end{aligned}
$$



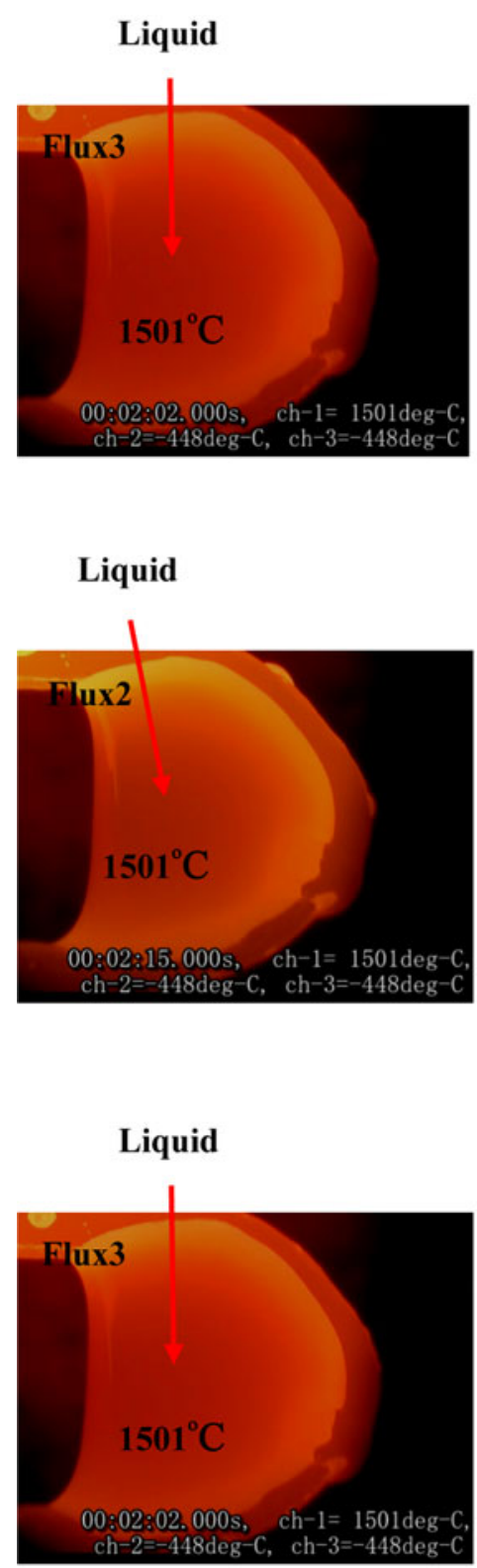

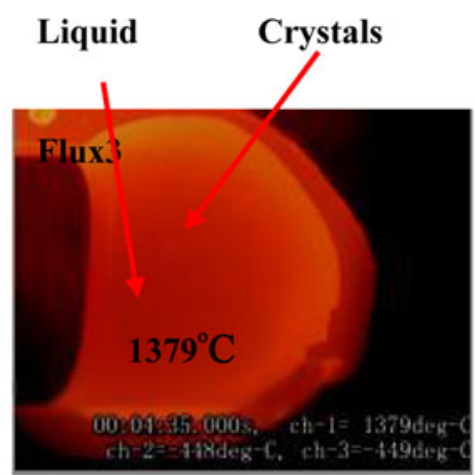

(a)

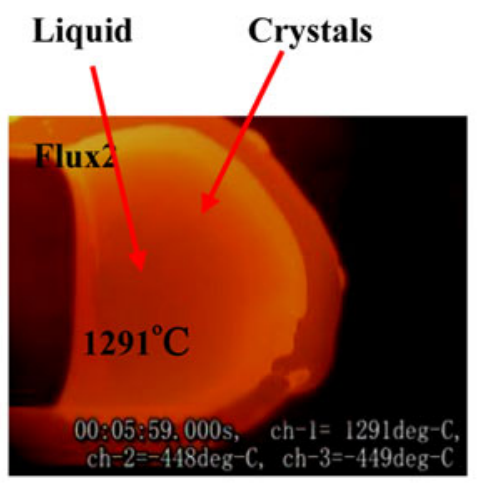

(b)
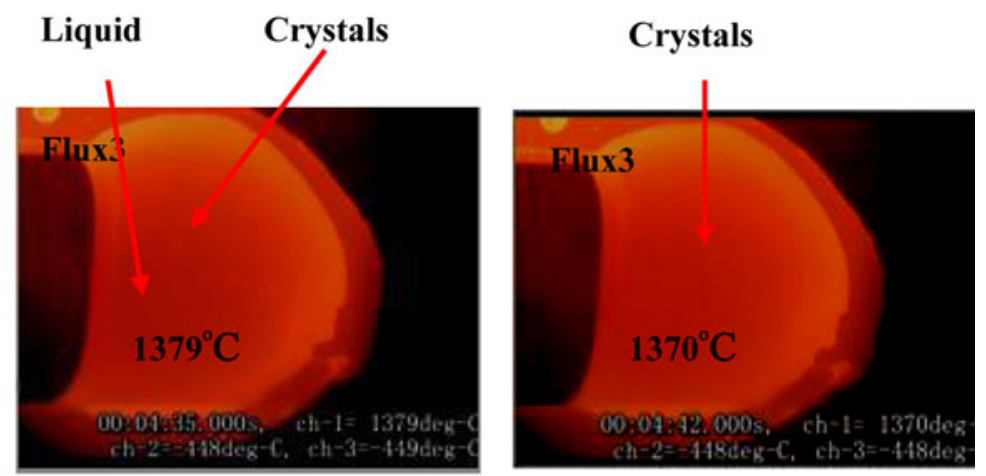

(c)
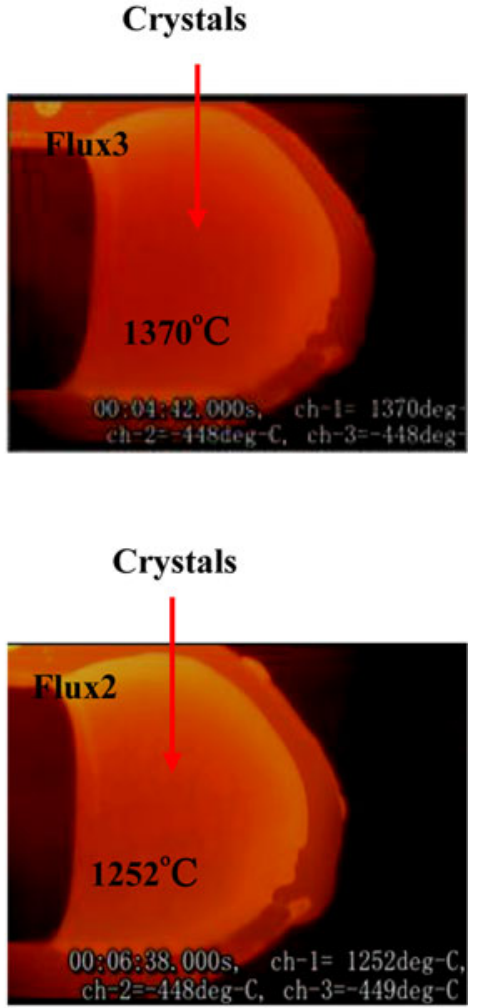

Crystals

Fig. 13-Crystallization behavior of mold fluxes at continuous cooling period: (a) flux 1, (b) flux 2, and (c) flux 3.

For flux 2 and flux $3, T_{1}$ stands for interfacial temperature between the layer of crystal and liquid $\left(T_{\mathrm{cl}}\right)$ that was determined as the solidification temperature during continuous cooling through SHTT shown in Figure 13, $T_{2}$ is the interface temperature between the bottom surface of solid flux and air gap $\left(T_{\mathrm{ms}}\right)$ that was calculated as Eq. [5], where $T_{\mathrm{m}}$ represents the top surface temperature of copper mold that could be calculated by the in-mold temperature gradient, $R_{\text {int }}$ means the interfacial thermal resistance, and $q_{\mathrm{obs}}$ is the measured heat flux at steady state.

$$
T_{2}=T_{m s}=T_{\mathrm{m}}+R_{\mathrm{int}} * q_{\mathrm{obs}}
$$

For flux 1, $T_{1}$ stands for interfacial temperature between the layer of glass and crystal that was deter- mined as the onset crystallization (glass transform) temperature $\left(T_{\mathrm{gc}}\right)$ during continuous heating process through SHTT as shown in Figure 12. $T_{2}$ is also the interface temperature between the bottom surface of solid flux and air gap $\left(T_{\mathrm{ms}}\right)$. The schematic figure of above illustration was given in Figure 14.

For Eqs. [3] and [4], $d$ is the thickness of glassy layer for flux 1 and crystalline layer for flux 2 and flux 3, and $K_{\text {cond }}$ is the thermal conductivity coefficient of the solid mold flux. The values were employed as 1.0 to $1.2 \mathrm{~W} \mathrm{~m}^{-1} \mathrm{~K}^{-1}$ for glassy flux film and 1.6 to $1.8 \mathrm{~W}$ $\mathrm{m}^{-1} \mathrm{~K}^{-1}$ for crystalline layer as in our previous study. ${ }^{[24]}$

The radiative thermal conductivity $K_{\text {rad }}$ of the solid flux was then calculated with Eqs. [6] and [7]. 


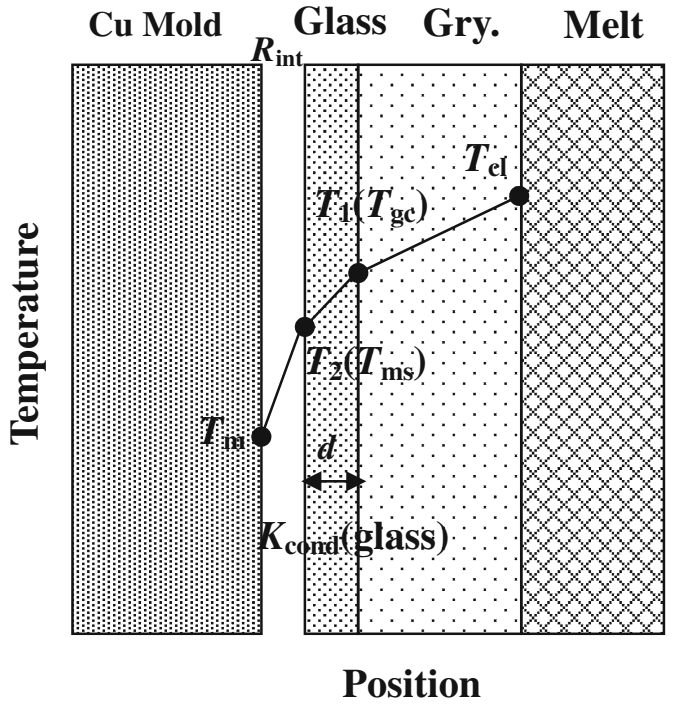

(a)

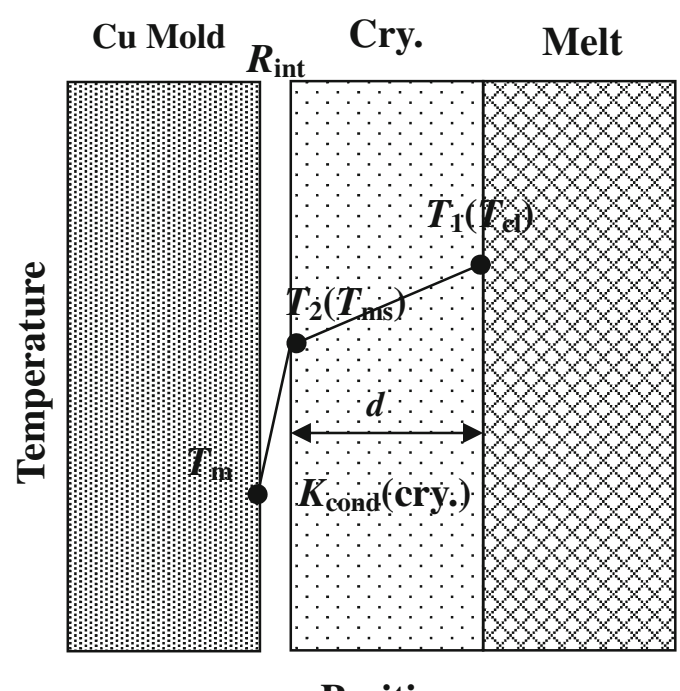

Position

(b)

Fig. 14-Schematic of temperature distribution across mold flux film: (a) for flux 1 and (b) for flux 2 and flux 3.

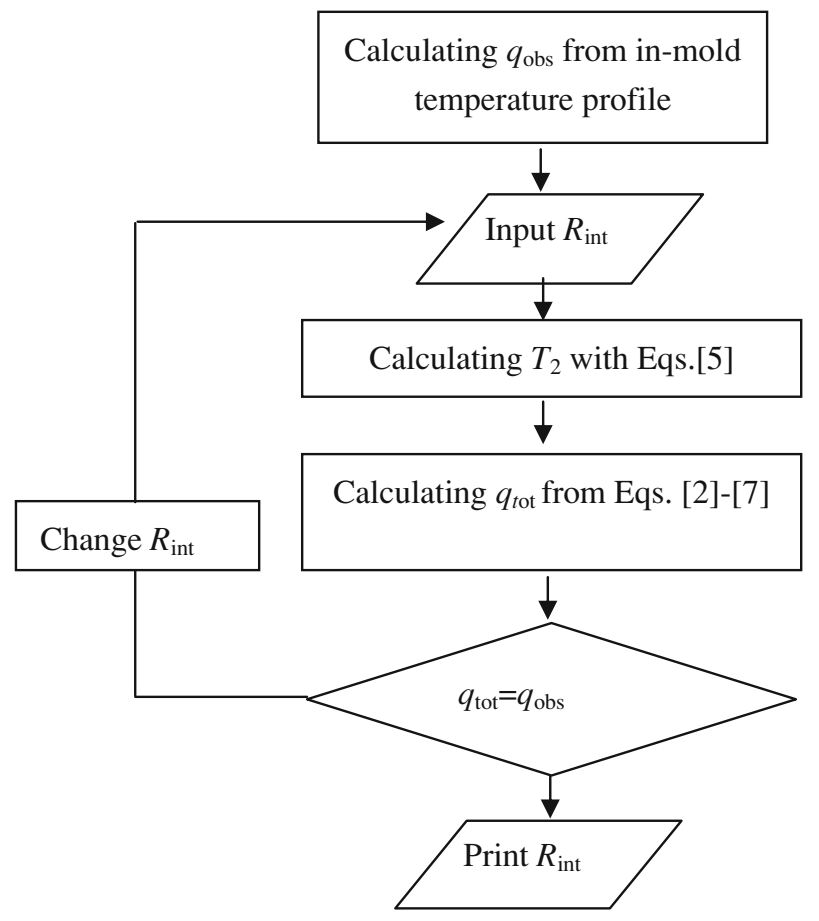

Fig. 15-The flow chart for calculating $R_{\text {int }}$.

$$
\begin{gathered}
K_{\mathrm{rad}}=\beta \frac{\left(T_{1}^{4}-T_{2}^{4}\right) d}{T_{1}-T_{2}} \\
\beta=\frac{n^{2} \sigma}{0.75 \alpha d+\varepsilon_{1}^{-1}+\varepsilon_{2}^{-1}-1}
\end{gathered}
$$

where $n$ is the refractive index that is referred to be $1.6 ; \sigma$ is the Stefan-Boltzmann constant, at $5.6705 \times 10^{-8}$ $\left(\mathrm{W} /\left(\mathrm{m}^{2} \mathrm{~K}^{4}\right) ; \varepsilon\right.$ represents the emissivity, at 0.92 for glass,
Table IV. Parameters for Interfacial Thermal Resistance $\left(R_{\text {int }}\right)$ Calculations

\begin{tabular}{lcccc}
\hline & & & $D$ & $K_{\text {cond }}$ \\
& $T_{1}\left[\mathrm{~K}\left({ }^{\circ} \mathrm{C}\right)\right]$ & $T_{\mathrm{m}}\left[\mathrm{K}\left({ }^{\circ} \mathrm{C}\right)\right]$ & $(\mathrm{mm})$ & $\left(\mathrm{W} /\left(\mathrm{m}^{2} \mathrm{~K}^{4}\right)\right.$ \\
\hline Flux1 & $1190(917)$ & $438.4(165.4)$ & 0.33 & 1.2 \\
Flux2 & $1564(1291)$ & $429.5(156.5)$ & 1.52 & 1.8 \\
Flux3 & $1662(1389)$ & $423(150)$ & 2.16 & 1.8 \\
\hline
\end{tabular}

0.7 for crystalline mold flux, and 0.4 for copper mold individually ${ }^{[27]}$; and $\alpha$ is the absorption coefficient of solid mold fluxes, at $400 \mathrm{~m}^{-1}$ for glass and $4500 \mathrm{~m}^{-1}$ for crystal. ${ }^{[28]}$

Therefore, the interfacial thermal resistance $R_{\text {int }}$ could be computed through the above equations as the flow chart shown in Figure 15, where the parameters used for the calculation were shown in Table IV.

The interfacial thermal resistance values were then calculated as $7.6 \times 10^{-4} \mathrm{~m}^{2} \mathrm{~K} / \mathrm{W}$ for flux 1 , and $10.3 \times 10^{-4}$ and $12.6 \times 10^{-4} \mathrm{~m}^{2} \mathrm{~K} / \mathrm{W}$ for flux 2 and flux 3 , respectively.

\section{CONCLUSIONS}

In this article, the IET was developed to study the crystallization and melting properties for different mold fluxes, where a liquid layer at the top and a solid layer in contact with copper mold with the degree of varying crystallization could be achieved when the mold slags were subjected to the heat fluxes that are similar to the real caster. With the combination of SHTT, the heattransfer phenomenon across mold flux to the mold could be successfully investigated, and important conclusions were made as follows:

1. The heat flux measurements indicated that the crystallization and the melting behavior of mold flux 
have significant impacts on the heat-transfer rate. The mold flux with a higher basicity for casting medium carbon steel, which usually tends to be fully crystallized, resulted in a rougher bottom surface and larger interfacial thermal resistance, which in turn retarded the heat-transfer rate in the mold.

2. The melting of the mold slag would enhance the overall heat-transfer rate as the exothermic curve shown in the melting experiments. Comparing flux 2 and flux 3, flux 2 with a lower solidification temperature would result in a thicker liquid layer, and its overall heat-transfer rate is higher than that of flux 3, even if their solid layer were all fully crystallized.

3. It takes longest time for flux 3 to initiate crystallization (from IET tests) due to its highest crystallization temperature, which was also suggested from its SHTT results. The melting and crystallization behaviors of all the slags obtained from both SHTT and IET are consistent so that flux 3 has a strongest crystallization tendency, and it owns the highest melting temperature zone and solidification temperature, which leads to the lowest heat-transfer rate in the mold.

\section{ACKNOWLEDGMENTS}

The work was supported by NSFC (51150110476), International Science \& Technology Cooperation Program of China (2011DFA71390), and the Fundamental Research Funds for the Central Universities (2011JQ010).

\section{REFERENCES}

1. M. Hayashi, T. Watanabe, H. Nakada, and K. Nagata: ISIJ Int., 2006, vol. 46 (12), pp. 1805-09.

2. K.C. Mills, A.B. Fox, Z. Li, and R.P. Thackray: Proc. VII Int. Conf on Molten Slags, Fluxes and Salts, The South African Institute of Mining and Metallurgy, Cape Town, South Africa, 2004, p. 713.

3. R. Saraswat, D.M. Maijer, P.D. Lee, and K.C. Mills: ISIJ Int., 2007, vol. 47 (1), pp. 95-104.
4. H. Nakada, M. Susa, Y. Seko, M. Hayashi, and K. Nagata: ISIJ Int., 2008, vol. 48 (5), pp. 446-53.

5. L. Zhou, W. Wang, F. Ma, J. Li, J. Wei, H. Matsuura, and F. Tsukihashi: Metall. Mater. Trans. B, 2012, vol. 43B, pp. 354-62.

6. Y. Meng and B.G. Thomas: ISIJ Int., 2006, vol. 46 (5), pp. 660-69.

7. K.C. Mills, A.B. Fox, Z. Li, and R.P. Thackray: Ironmaker Steelmaker, 2005, vol. 32, p. 26.

8. A. Yamauchi, K. Sorimachi, T. Sakuraya, and T. Fujii: ISIJ Int., 1993, vol. 33 (1), pp. 140-47.

9. M. Susa, A. Kushimoto, H. Toyota, M. Hayashi, R. Endo, and Y. Kobayashi: ISIJ Int., 2009, vol. 49 (11), pp. 1722-29.

10. H. Nakada, M. Susa, Y. Seko, M. Hayashi, and K. Nagata: ISIJ Int., 2008, vol. 48 (5), pp. 446-53.

11. H. Nakada and K. Nagata: ISIJ Int., 2006, vol. 46 (3), pp. 441-48.

12. H.G. Ryu, Z.T. Zhang, J.W. Cho, G.H. Wen, and S. Sridhar: ISIJ Int., 2010, vol. 50 (8), pp. 1142-50.

13. C. Orrling: Ph.D. Dissertation, Carnegie Mellon University, Pittsburgh, PA, 2000.

14. Y. Kashiwaya, C.E. Cicutti, A.W. Cramb, and K. Ishii: ISIJ Int., 1998, vol. 38 (4), pp. 348-56.

15. J. Diao, B. Xie, J.P. Xiao, and C.Q. Ji: ISIJ Int., 2009, vol. 49 (11), pp. $1710-14$.

16. H. Shibata, K. Kondo, M. Suzuki, and T. Emi: ISIJ Int., 1996, vol. 36, pp. S179-82.

17. J.W. Cho, T. Emi, H. Shibata, and M. Suzuki: ISIJ Int., 1998, vol. 38 (5), pp. 440-46.

18. G. Wen, S. Sridhar, P. Tang, X. Qi, and Y. Liu: ISIJ Int., 2007, vol. 47 (8), pp. 1117-25.

19. W. Wang and A.W. Cramb: ISIJ Int., 2005, vol. 45 (12), pp. 1864 70.

20. W. Wang, K. Gu, and L. Zhou: ISIJ Int., 2011, vol. 51 (11), pp. $1838-45$.

21. J. Cho, H. Shibata, T. Emi, and M. Suzuki: ISIJ Int., 1998, vol. 38 (3), pp. $268-75$.

22. J.V. Beck: 1HCP1D: A Program for Calculating Surface Heat Fluxes from Transient Temperatures Inside Solides, Version 5.31, Beck Engineering Consultants Company, Houston, TX, 1997.

23. A. Badri, T.T. Natarajan, C.C. Snyder, K.D. Powers, F.J. Mannion, and A.W. Cramb: Metall. Mater. Trans. B, 2005, vol. 36B, pp. 355-71.

24. K. Gu, W. Wang, L. Zhou, F. Ma, and D. Huang: Metall. Mater. Trans. B, 2012, vol. 43B, pp. 937-45.

25. W. Wang and A.W. Cramb: Steel Res. Int., 2010, vol. 81, pp. 446554.

26. W. Wang, L.J. Zhou, and K.Z. Gu: Mater. Int., 2010, vol. 16 (6), pp. 913-20.

27. Y. Shiraishi: Handbook of Physo-Chemical Properties at High Temperature, ISIJ, Tokyo, Japan, 1988.

28. W. Wang: Ph.D. Dissertation, Carnegie Mellon University, Pittsburgh, PA, 2007. 